\title{
Optimization of hydraulic fracturing with rod-shaped proppants for improved recovery in tight gas reservoirs
}

\author{
Faisal Mehmood $\mathbb{D} \cdot$ Jianxing Liao $\cdot$ Michael Z. Hou \\ Muhammad Khurram Zahoor • Ying Xiong
}

Received: 21 June 2021 / Accepted: 7 January 2022 / Published online: 4 February 2022

(C) The Author(s) 2022

\begin{abstract}
Due to the increasing demand and importance of natural gas in the global energy mix, its expeditious recovery is crucial, especially from large-scale unconventional geo-resources. Hydraulic stimulation is an established means of productivity increase especially from tight gas reservoirs. The fracture conductivity generally depends on proppant properties, particularly the shape. Therefore, in this research, the effect of using rod-shaped proppants was investigated. Using rod-shaped proppants instead of conventional spherically shaped proppants, can make a significant difference. Due to the cylindrical
\end{abstract}

\footnotetext{
F. Mehmood $(\bowtie) \cdot$ M. Z. Hou

Institute of Subsurface Energy Systems, Clausthal

University of Technology, 38678 Clausthal Zellerfeld,

Germany

e-mail: faisal.mehmood41@yahoo.com;

jxliao@gzu.edu.cn

F. Mehmood · M. Z. Hou · Y. Xiong

Research Centre of Energy Storage Technologies,

Clausthal University of Technology, 38640 Goslar,

Germany

F. Mehmood · M. K. Zahoor

Department of Petroleum and Gas Engineering, University

of Engineering and Technology Lahore, Lahore 54890,

Pakistan

J. Liao $(\bowtie)$

College of Civil Engineering, Guizhou University,

Guiyang 550025, China

e-mail: faisal.mehmood41@yahoo.com;

jxliao@gzu.edu.cn
}

shape, higher porosity and permeability are generated, resulting in better conductivity fractures. Thus, to analyze the effect of different proppant shapes on post-fracture performance, a production model was implemented in the FLAC $3 \mathrm{D}^{\text {plus }}$-TMVOC framework. Later, an in-depth sensitivity analysis was performed to investigate the effects of the proppant shape, size, strength, and effective stress on the fracture aperture reduction and conductivity due to proppant deformation and embedment. The application to a generic model revealed that recovery can be increased by about 7\% using aspect ratio 1 rod-shaped proppant with the same diameter as the spherical proppant. Then, increasing the rod-shaped proppant size from an aspect ratio of 1-10 can significantly increase the gas recovery by $13 \%$ but results in higher proppant deformation. Finally, the application of rod-shaped proppants to fracturing proposals in well $\mathrm{x}$ in a tight gas reservoir of Germany showed that the recovery could be significantly improved if spherical proppants are replaced with rod-shaped proppants.

\section{Article highlights}

- Implementation of the post-fracture performance model based on rod-shaped and spherical proppants in the FLAC3D ${ }^{\text {plus }}$-TMVOC framework.

- Investigating the effect of proppant shape, size, strength, and effective stress on the fracture conductivity due to proppant embedment and deformation. 
- Significantly higher productivity can be achieved using rod-shaped proppants than spherical proppants.

Keywords Rod-shaped proppants $\cdot$ Spherical proppants $\cdot$ Fracture conductivity $\cdot$ Hydraulic fracturing $\cdot$ Tight gas $\cdot$ Post-fracture performance

\section{Introduction}

The exploitation of the geo-resource of conventional oil and gas for more than a century has led to industrial development. However, substantial resources remain underground due to lower recoveries (Jia 2017). The production from conventional petroleum resources, characterized by high porosity and permeability, is declining, as the high-quality resource of easy to extract conventional reservoirs is limited. Around $80 \%$ of total resources are unconventional and can be mainly characterized as tight oil, tight gas, shale gas, shale oil, coal-bed methane and gas hydrates (Leimkuhler and Leveille 2012; Zou et al. 2013).

Natural gas is a cleaner fossil fuel compared to oil and coal with fewer emissions and pollutants due to lower $\mathrm{CO}_{2}$ to energy content ratio. Natural gas produces only $117 \mathrm{lbs}$ of $\mathrm{CO}_{2}$ per million British thermal units (Btu) compared with $161 \mathrm{lbs}$ of $\mathrm{CO}_{2}$ per million Btu and $205 \mathrm{lbs}$ of $\mathrm{CO}_{2}$ per million Btu for diesel and coal (bituminous), respectively (US EIA, 2021). It will play an increasing role in the global energy mix and can serve as a bridge fuel for the transition to renewable energy. The share of natural gas in primary energy reached 23\% in 2019. Due to continuous rise in energy demand, it is expected that the peak global gas production will remain from 3.7 to 6.1 trillion $\mathrm{m}^{3}$ (tcm) per year between 2019 and 2060 (IEA 2020; Wang and Bentley 2020; Zou et al. 2014). According to the international energy outlook, an increase of more than $40 \%$ in global gas consumption is expected between 2018 and 2050 (EIA 2019).

Therefore, efficient development of unconventional resources is essential for global energy security. Hence, the focus of this work is on the exploitation of the geo-resource of tight gas reservoirs, which can be defined as lower permeability and porosity reservoirs accumulated over a large area, requiring a change in the permeability or permeability-viscosity ratio to produce at commercial production rates. Therefore, well stimulation techniques are applied to enhance their productive potential (Zou et al. 2013). Hydraulic stimulation of wellbores is the first means of choice for improving productivity of tight gas reservoirs by creating highly conductive fluid flow paths. Pressurized fluid injection results in fracture initiation and propagation normal to the minimum principal stress due to tensile failure (Economides 2007; Economides and Nolte 2000). Since the late 1940s, millions of fracturing treatments have been performed, increasing the recoverable reserves apart from stimulating production (Clark 1949; Leimkuhler and Leveille 2012; Montgomery and Smith 2010; Zou et al. 2013).

Compared to rock grains, proppants are large diameter particles, and their purpose is not only to keep a fracture open but also provide sufficient porosity and permeability to the reservoir fluid so that commercial production becomes possible. As the fracture closure occurs under the influence of closure stress and fluid leakoff to surrounding formations, the width of the fracture decreases, and proppants contact the walls of the fracture. Fracture conductivity, dependent on proppant pack permeability, is a measure of its ability of how well it can transmit reservoir fluid to the wellbore. The proppant composition, strength, grain size distribution, roundness, density, pack permeability, and proppant degradation over time, affect fracture conductivity (Economides and Nolte 2000). Higher diameter proppants offer higher permeabilities, but as the proppant size increases, the crush resistance decreases. Generally, with an increase in strength, the proppant density also increases (Economides 2007).

The first hydraulic fracturing operation in 1947 used silica sand proppants (Liang et al. 2016). Since then, many materials have been employed for proppants, such as natural sand, ceramic, resin coated sand, sintered bauxite, and kaolin. Generally sand and ceramic proppants have been used (Hellmann et al. 2009; Liang et al. 2016; Montgomery and Smith 2010). These proppants have their own strengths depending upon the material. They can be categorized as low, medium, or high strength proppants. Some of the commonly used proppants and their strengths at a conductivity of $1750 \mathrm{mD}$-ft are presented in Fig. 1 (Liang et al. 2016).

Based on the literature study, mathematical models have been developed, and simulations have been 


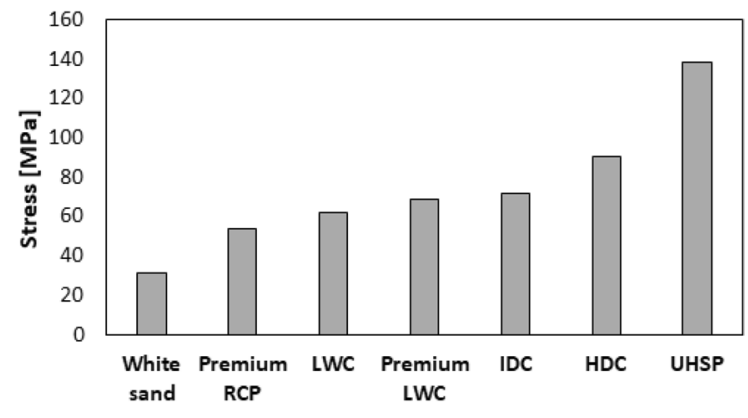

Fig. 1 Conductivity of proppants having different strengths (Liang et al. 2016)

performed for porosity, permeability, fracture conductivity, and proppant embedment and deformation, previously. Moreover, experiments and field applications have been discussed; however, post-fracture production forecasts for rod-shaped proppants based on the proppant and formation mechanical properties, fracture geometry, and in-situ stress conditions have not been examined through numerical modeling. Therefore, it is imperative to numerically investigate the performance of different proppants in the production phase. In this work, a production model is implemented in FLAC3D ${ }^{\text {plus }}$-TMVOC framework to numerically analyze the production performance of hydraulic fractures with different proppants considering their shape, size, strength, formation properties and stress conditions during the post-stimulation production period.

\section{Rod-shaped proppants}

Fracture conductivity depends on permeability, which depends on the porosity of the proppant pack; thus, changing the shape of proppant can make a significant difference. Spherical proppants are isotropic concerning shape, which leads to a lower space between particles. Rod-shaped proppants that are cylindrical, can provide a much broader range of packing arrangements than conventional proppants due to shape anisotropy where the concept of the aspect ratio (i.e., the length to the diameter of the proppant) is used. As the aspect ratio increases, the porosity and permeability of the proppant pack increases. Compared to spherical proppants, up to three times higher conductivity fractures can be created with rod-shaped proppants.
In baseline conductivity testing, rod-shaped proppants with an average diameter equivalent to a $12 / 18$ mesh intermediate strength proppant (ISP) with an aspect ratio of 2 generated a conductivity of around 73,000 mD.ft and 33,000 mD.ft at closure stresses of 2000 psi and 6000 psi compared with 27,000 mD.ft and 20,000 mD.ft for 12/18 ISP, respectively (Cheremisin et al. 2011; Schlumberger 2013). The elongated shape results in higher porosity, permeability and resultant conductivity for rod-shaped proppants. According to Osiptsov (2017), spatially periodical packing of spheres, ellipsoids, and cylinders generate porosity values of $0.42,0.60$, and 0.65 , respectively. A cylindrical proppant with an aspect ratio of 3 can generate a volume equivalent to a spherical proppant whose diameter is $40 \%$ more. A unique consolidated proppant pack can be created due to the cylindrical shape which can resist the proppant flowback. Another added advantage is the mobility increase of a high-viscosity slurry, which can help in quick fracture cleanup due to higher available permeability (Cheremisin et al. 2011; Jia et al. 2019; Li et al. 2015; McDaniel et al. 2010; Osiptsov 2017; Schlumberger 2013, 2015; Soetikno et al. 2014). The field tests indicated that the friction pressure for rodshaped proppants was $492 \mathrm{psi} / 1000 \mathrm{ft}$, significantly lower than $543 \mathrm{psi} / 1000 \mathrm{ft}$ for spherical particles for an equivalent volume of particles in the slurry. The main reason is the alignment of elongated particles in the direction of the fluid flow, reducing the turbulence and lowering the friction pressure loss. Therefore, a rod-shaped proppant injection, compared to spherical proppant, can provide the added advantage of lower surface injection pressure requirements due to the lower friction pressure loss. During the settling phase until fracture closure, the fracture conductivity can be reduced if the proppants settle perpendicular to the flow direction. However, multiple slot flow and proppant settling tests revealed that the proppant alignment after settling was completely random (McDaniel et al. 2010). Moreover, the proppant diameter should be chosen according to the fracture aperture to avoid any entry restrictions in the fracture. Figure 2 presents spherical and rod-shaped proppant shapes and a rod-shaped proppant pack.

According to Osiptsov (2017), periodical packing of cylinders with an aspect ratio 5 yielded $23 \%$ more porosity than spherical proppants. The numerical simulation results with different proppants exhibited the 
Fig. 2 Spherical and rodshaped proppant shapes and an example of rod-shaped proppant pack (Li et al. 2015; Wilson 2015)

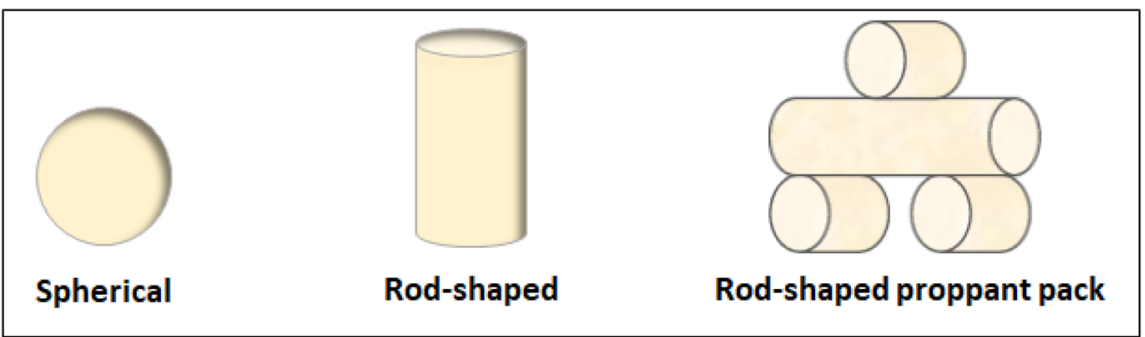

maximum porosity and permeability for cylindrical proppant packs. Compared to conventional proppants, the initial and retained conductivity are enhanced using rod-shaped proppants. Successful field trials have demonstrated that the existing wellsite equipment can perform the fracturing operation with this new proppant even at high volumes of 100,000 lbm per job. These proppants reduce friction pressure, which lowers the surface injection pressure, and significantly enhance the productivity index compared to conventionally fractured wells (McDaniel et al. 2010). Longer effective fracture half-lengths due to better and quicker cleanup and higher conductivity of rod-shaped proppants increased the cumulative production by at least $12 \%$ after a six-month production period compared to hydraulic fracturing with conventional proppants (Carpenter 2016). Combining the channel fracturing technique with rod-shaped proppants increased the well productivity in the depleted Devonian formations in the Orenburg region in Russia. Due to their shape, rod-shaped proppants can hold each other through mechanical means whereas, the proppant pack stability is based on chemical bonds that depend on temperature or time of activation for conventional proppants, such as resin coated proppants. Therefore, rod-shaped proppant injection especially at the final stage of fracturing provides high conductivity in the near wellbore region and minimizes the proppant flowback problem (Schlumberger 2015; Wilson 2015). Similarly, applying a high strength ceramic rod-shaped proppant during the hydraulic fracturing operation in a petroleum field in Indonesia increased production, adding valuable reserves (Soetikno et al. 2014).

\section{Numerical modeling}

The mathematical models developed by Jia et al. (2019) and $\mathrm{Li}$ et al. (2015) are incorporated into
FLAC3D plus -TMVOCMP framework (Gou et al. 2015; Li 2018; Liao 2020) to simulate the effect of different proppants on fracture conductivity and productivity. According to Zhou and Hou (2013), FLAC3D (Fast Lagrangian Analysis of Continua in 3D) (ITASCA, 2009) was equipped with hydraulic fracturing model based upon tensile failure criterion making it FLAC $3 D^{\text {plus }}$. In contrast, TMVOC is multiphase multicomponent fluid flow simulator based on the Darcy law (Pruess and Batistelli 2002). The change in fracture conductivity due to proppant embedment and deformation is dependent on proppant size, strength contrast with the formation (mechanical properties such as elastic-modulus and Poisson's ratio) and effective stress. Figure 3 describes the concept of change in the fracture width due to proppant embedment and deformation, where 'wd' and 'we' represent the reduced fracture width due to deformation and embedment, respectively.

The proppant embedment and deformation depend on the effective stress, the strength contrast between proppant and formation and the proppant size. The proppant embedment on one wall of a fracture or on one side is given by the following Eq. 1 (Jia et al. 2019):

$E^{\prime \prime}=\sigma^{\prime} d_{r}\left[V_{2}\left[1+\ln \left\{\frac{2 l_{r}^{2}}{\left(V_{1}+V_{2}\right) \sigma^{\prime}}\left(\frac{1}{d_{r}}\right)^{2}\right\}\right]-V_{1} \ln \left(\frac{V_{1}+V_{2}}{V_{1}}\right)\right]$

The proppant deformation can be mathematically written as follows:

$D^{\prime \prime}=\sigma^{\prime} w_{i} V_{1}\left[1+\ln \left\{\frac{2 l_{r}^{2}}{V_{1} \sigma^{\prime}}\left(\frac{1}{d_{r}}\right)^{2}\right\}\right]$

where $V_{1}=\left(1-v_{1}^{2}\right) / \pi E_{1}$ and $V_{2}=\left(1-v_{2}^{2}\right) / \pi E_{2}$. In addition, $E^{\prime \prime}$ is the proppant embedment [mm], and $D^{\prime \prime}$ is the proppant deformation. Additionally, $\sigma^{\prime}$ denotes the effective stress [MPa]. Moreover, $v_{1}$ represents Poisson's ratio of proppant, and $v_{2}$ represents 


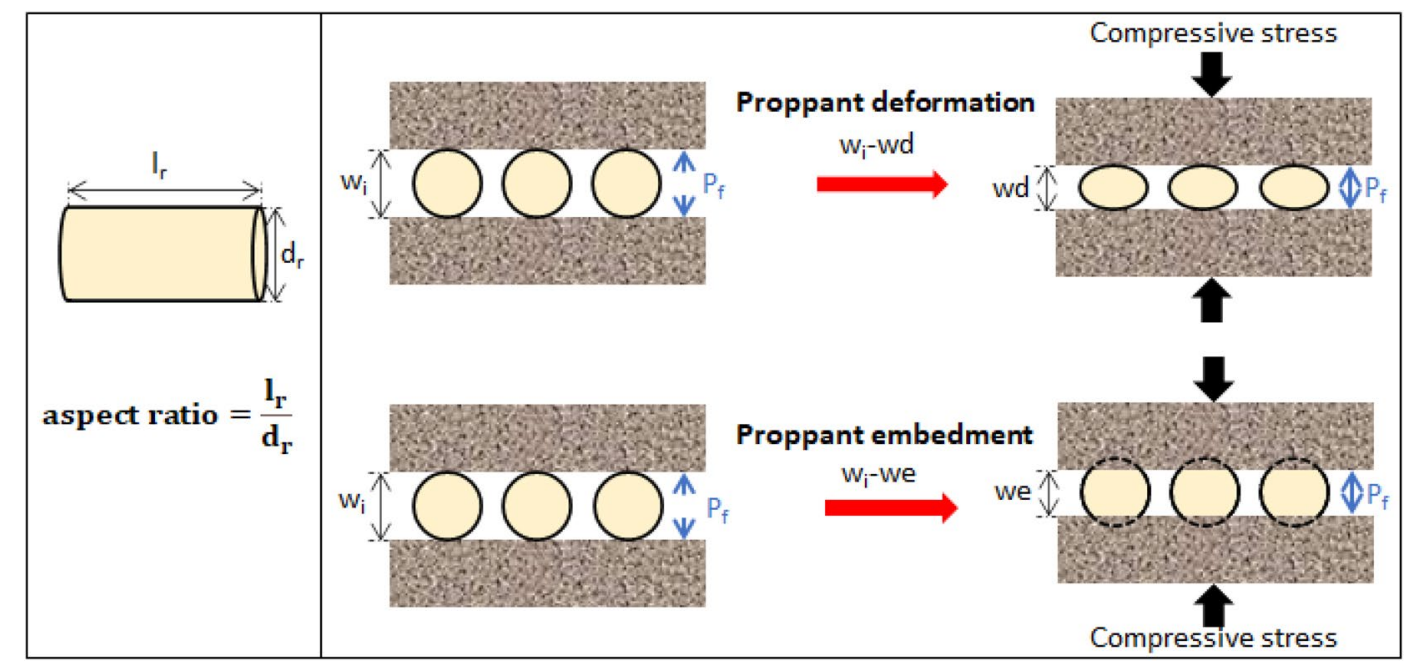

Fig. 3 Rod-shaped proppant dimensions and concept of fracture width change due to deformation and embedment $\left(l_{r}\right.$ : proppant length, $\mathrm{d}_{\mathrm{r}}$ : proppant diameter, $\mathrm{w}$ : width, wd: reduced

Poisson's ratio of formation. The variable $E_{1}$ denotes the elastic modulus of the proppant [MPa], and $E_{2}$ denotes the elastic modulus of the formation. Finally, $l_{r}$ indicates the proppant length [mm], $d_{r}$ is the proppant diameter $[\mathrm{mm}]$, and $w_{i}$ is the initial fracture width $[\mathrm{mm}]$.

The change in fracture aperture due to a reduction in the fracture width on one side of the fracture should be equal to the combined effect of the embedment and deformation:

$C^{\prime \prime}=E^{\prime \prime}+D^{\prime \prime}$

To determine the total change in fracture width, the change in fracture aperture on one side, as given by Eq. (3) is multiplied by two and subtracted from the initial width:

$w=w_{i}-2 C^{\prime \prime}$

where $C^{\prime \prime}$ is the fracture width reduction on one side $[\mathrm{mm}]$ and $w$ is the fracture width after width reduction $[\mathrm{mm}]$.

Fracture conductivity is primarily dependent on the permeability, depending on the proppant pack porosity. Therefore, the permeability is defined in terms of the porosity using a commonly used correlation based on the Kozeny-Carman model and width due to deformation, we: reduced width due to embedment, $\mathrm{P}_{\mathrm{f}}$ : pressure in the fracture zone) modified from (Jia et al. 2019; Li et al. 2015)

mathematically expressed by Eq. (5) (Jia et al. 2019; Li et al. 2017, 2015):

$k_{f}=\frac{\varnothing r^{2}}{8 \tau^{2}}$

where $k_{f}$ denotes the permeability of the propped fracture $\left[\mu \mathrm{m}^{2}\right], \varnothing$ represents the porosity $[-], r$ is the pore throat radius $[\mu \mathrm{m}]$, and $\tau$ denotes the pore tortuosity [-].

The fracture starts to close once the pressure inside the fracture becomes lower than the closure stress. The production operation depletes the reservoir pressure which further increases the effective stress on the proppants. Under compaction, the close packing of proppants occurs, and the porosity of rod-shaped proppants can be determined using the concept of the change in fracture aperture at the corresponding effective stress:

$\varnothing=\frac{w_{i}\left(1-\frac{8.97}{\frac{d_{r}}{l_{r}}+\frac{l_{r}}{d_{r}}+13.325}\right)-2 D^{\prime \prime}}{w_{i}-2 D^{\prime \prime}}$

Based upon the relationship expressed by Eq. (5), applying the porosity correlation (Eq. 6), the corresponding fracture permeability can be determined: 
$k_{f}=11.067 \frac{\left[w_{i}\left(1-\frac{8.97}{\frac{d_{r}}{l_{r}}+\frac{l_{r}}{d_{r}}+13.325}\right)-2 D^{\prime \prime}\right]\left(w_{i}-2 D^{\prime \prime}\right)^{2} d_{r}^{4 / 3} l_{r}^{2 / 3}}{w_{i}^{2}\left(w_{i}-2 D^{\prime \prime}\right)\left[0.5\left(\frac{w_{i}-2 D^{\prime \prime}}{w_{i}}\right)^{2}+1\right]}$

Similarly, the porosity and permeability correlations for spherical proppants are defined by Eqs. (8) and (9) (Li et al. 2015):

$\varnothing=\frac{w_{i} \varnothing_{i}-2 D}{w_{i}-2 D}$

$k_{f}=498.58 d_{r}^{2}\left[\frac{\varnothing_{i} w_{i}-2 D}{w_{i}-2 D}\right]$

The fracture conductivity can be defined as the ability of the fracture to transmit fluids to the wellbore and is mathematically expressed as follows (Economides and Nolte 2000; Prats 1961):

$F_{c}=k_{f} w_{i}$

For tight reservoirs, a more realistic approach is to add the ability of the reservoir to feed the fracture to the conductivity term (Eq. 10), making it a dimensionless fracture conductivity $F_{c d}$ (Eq. 11) (Economides and Nolte 2000):

$F_{c d}=\frac{k_{f} w_{i}}{k x_{f}}$

However, to investigate the effect of a hydraulic connection between the fracture and perforations, the effects of the position and proppant concentration with reference to the injection zone were added to Eq. (11) by Hou et al. (2021) to make it a weighted fracture conductivity:

$F_{c d, \text { weighted }}=\frac{\sum_{j=1}^{n} \frac{w_{i j} k f_{j}}{d_{i}} A_{j} \frac{c_{p}}{c_{\max }}}{\sum_{j=1}^{n} \frac{1}{d_{j}} A_{j} \frac{c_{p}}{c_{\max }}} \times \frac{1}{k x_{f}}$

where $w_{i}$ indicates the initial fracture width [m], $k f$ denotes the fracture permeability $\left[\mathrm{m}^{2}\right], d$ is distance between the fracture element and perforation [m], $A$ indicates the fracture element area $\left[\mathrm{m}^{2}\right], c_{p}$ is the proppant concentration, $c_{\max }$ represents the maximum proppant concentration, $k$ denotes the reservoir permeability $\left[\mathrm{m}^{2}\right], x_{f}$ is the fracture half-length $[\mathrm{m}]$, and $j$ indicates the $j$ th element in a model consisting of of $n$ elements.

The following correlations (Eq. 13) can be used to determine the decreased fracture conductivity due to fracture aperture reduction after production:

$$
\left\{\begin{array}{l}
F_{c}^{\prime}=k_{f}\left(w_{i}-2 C^{\prime \prime}\right) \\
F_{c d}^{\prime}=\frac{k_{f}\left(w_{i}-2 C^{\prime \prime}\right)}{k x_{f}} \\
F_{c d, \text { weighted }}{ }^{\prime}=\frac{\sum_{j=1}^{n} \frac{\left(w_{i}-2 C^{\prime \prime}\right)_{j} f_{j}}{d_{i}} A_{j} \frac{c_{p}}{c_{\max }}}{\sum_{j=1}^{n} \frac{1}{d_{j}} A_{j} \frac{c_{p}}{c_{\max }}} \times \frac{1}{k x_{f}}
\end{array}\right.
$$

The average permeability of the matrix zone containing the fracture element (as the fracture zone resides in the matrix zone) can be determined by the principle of superposition to model the fluid flow from the reservoir to the fracture and perform production simulation (Fig. 4).

The following equations define the permeabilities in three directions (i.e., $\mathrm{x}, \mathrm{y}$, and $\mathrm{z}$ ) to model the fluid exchange between matrix and fracture (Li 2018).

$k_{x}=\frac{x_{1} k_{1}+w_{f} k_{f}}{x_{1}+w_{f}}$

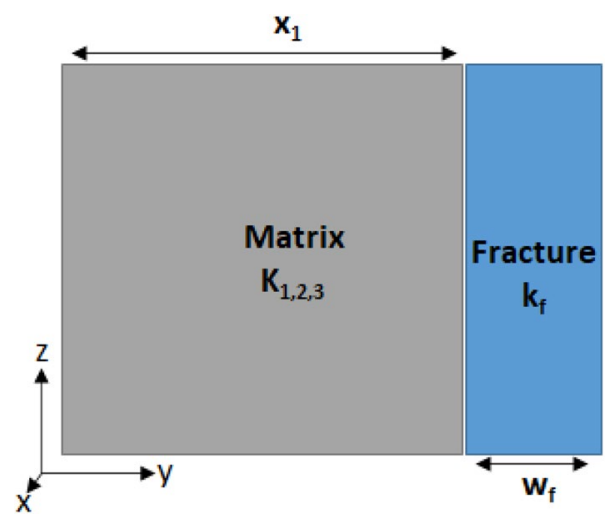

Fig. 4 Fracture zone permeability based on the principle of superposition (Li 2018) 
$k_{y}=\frac{x_{1}+w_{f}}{\frac{x_{1}}{k_{2}}+\frac{w_{f}}{k_{f}}}$

$k_{z}=\frac{x_{1} k_{3}+w_{f} k_{f}}{x_{1}+w_{f}}$

where, $k_{x}, k_{y}$, and $k_{z}$ indicate the zone permeability containing the fracture $\left[\mathrm{m}^{2}\right], k_{f}$ is the propped zone permeability $\left[\mathrm{m}^{2}\right], k_{1}, k_{2}$, and $k_{3}$ represent the matrix permeability in the $x, y$, and $z$ directions $\left[\mathrm{m}^{2}\right], x_{1}$ denotes the width of the matrix zone $[\mathrm{m}]$, and $w_{f}$ is the fracture width [m].

These models are implemented for post-fracture production performance. After the hydraulic fracturing operation, the created fracture geometry is assigned porosity and permeability according to the proppant selection (i.e., the diameter is specified in the case of the spherical proppant and the diameter and length in the case of the rod-shaped proppant). The proppant strength parameters are supplied. Then, the initial porosity and permeability values are calculated, and the initial fracture conductivity is determined according to the choice of proppant. After executing these calculations in FLAC3D, the simulation starts for production from a fractured reservoir. The data, such as porosity, permeability, stress, and so on, are sent to TMVOC, where the pressure, fluid flow, phase saturations and other aspects are determined. The data are then sent back, and new fracture width is determined based upon the change in the effective stress and the resultant proppant embedment and deformation. The simulation continues until the time limit provided. Figure 5 presents the detailed working of the post-fracture production model.

\section{Sensitivity analysis}

Simulations were performed in a generic model to investigate the effects of important factors, such as proppant shape, aspect ratio, strength contrast with formation, and effective stress, on fracture permeability, conductivity and long-term production performance. A 3D (1/4) model for a tight gas reservoir was generated in FLAC3D (ITASCA 2009) (Fig. 6a). The properties including porosity, permeability, elastic modulus, Poisson's ratio and density applied to the formations in the model are listed in Table 1. The model parameters and relative permeability and capillary pressure data were presented by Gou et al.

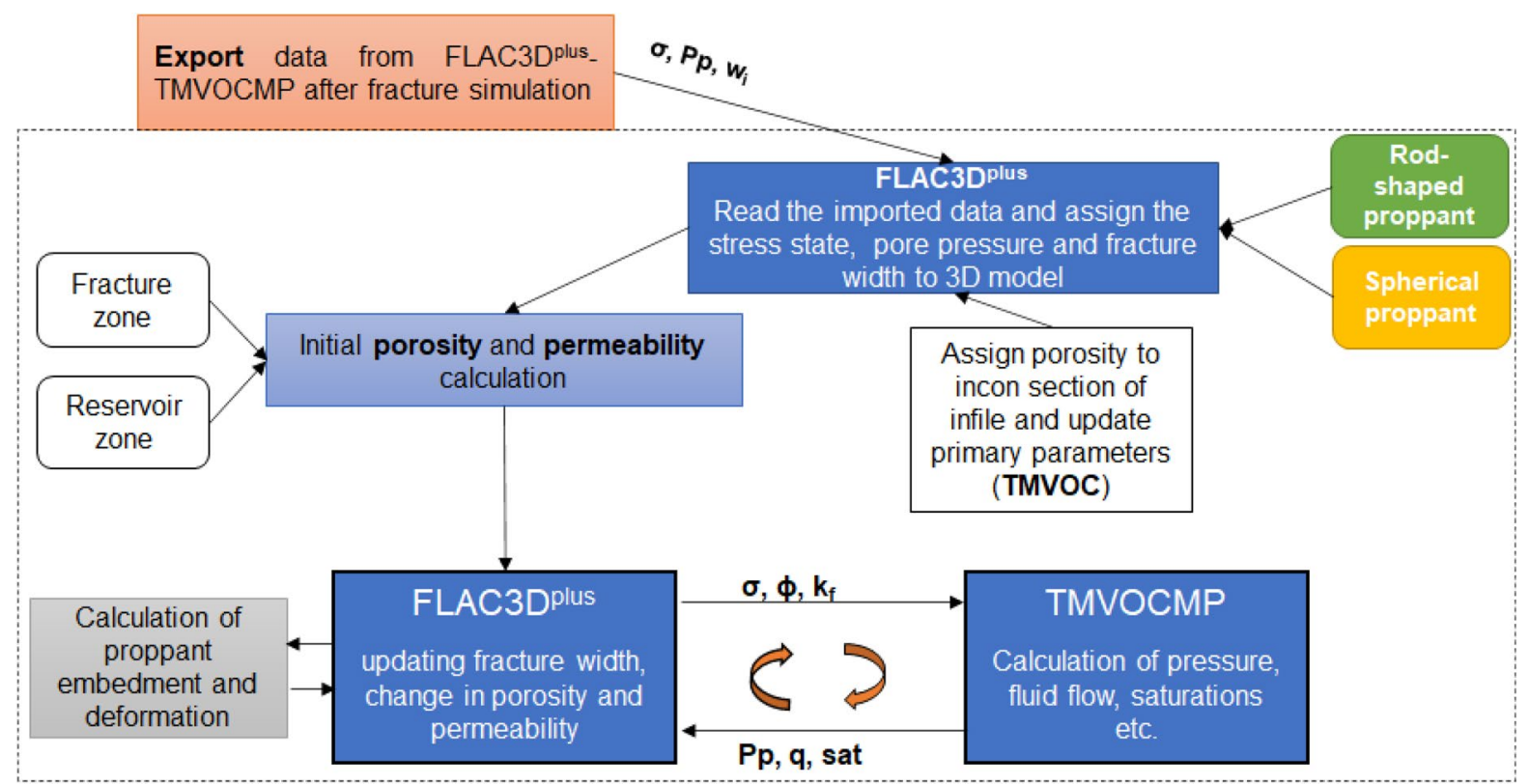

Fig. 5 Flowchart of different stages of numerical calculations and data sharing between software ( $w_{\mathrm{i}}$ : initial fracture width, $\sigma$ : stress state, $\varnothing$ : porosity, Pp: pore pressure, q: flowrate, sat: fluid saturation in different phases) 


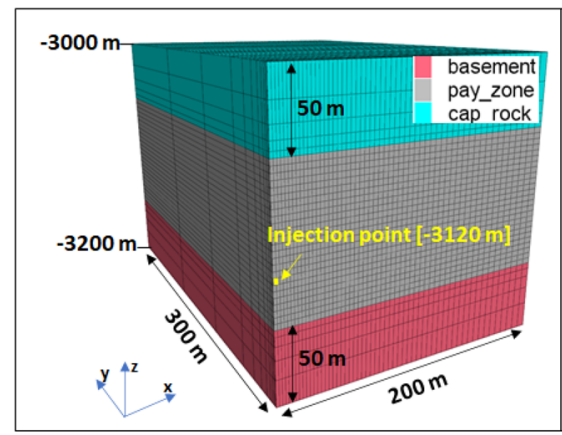

(a)

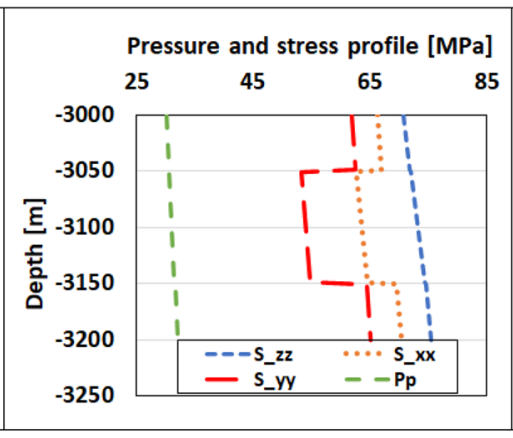

(b)

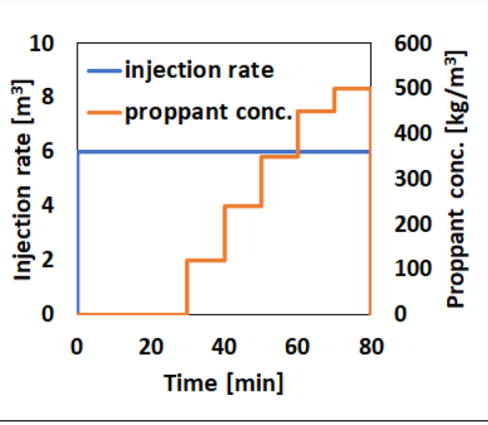

(c)

Fig. 6 a 3D generic quarter model, b pore pressure and stress profile, $\mathbf{c}$ injection schedule for fluid and proppants (S_zz: vertical stress, S_xx: maximum horizontal stress, S_yy: minimum horizontal stress, Pp: pore pressure) (Gou et al. 2015)

Table 1 Hydromechanical properties of formations in the model

\begin{tabular}{llllll}
\hline Formation type & Porosity $(-)$ & Permeability $\left(\mathrm{m}^{2}\right)$ & Elastic modulus $(\mathrm{GPa})$ & Poisson's ratio $(-)$ & Density $\left(\mathrm{kg} / \mathrm{m}^{3}\right)$ \\
\hline Caprock & 0.025 & $4 \mathrm{e}-17$ & 25 & 0.3 & 2650 \\
Payzone & 0.1 & $4 \mathrm{e}-15$ & 30 & 0.25 & 2600 \\
Basement & 0.025 & $4 \mathrm{e}-17$ & 25 & 0.3 & 2650 \\
\hline
\end{tabular}

Fig. 7 Fracture half-width at shutin and closure

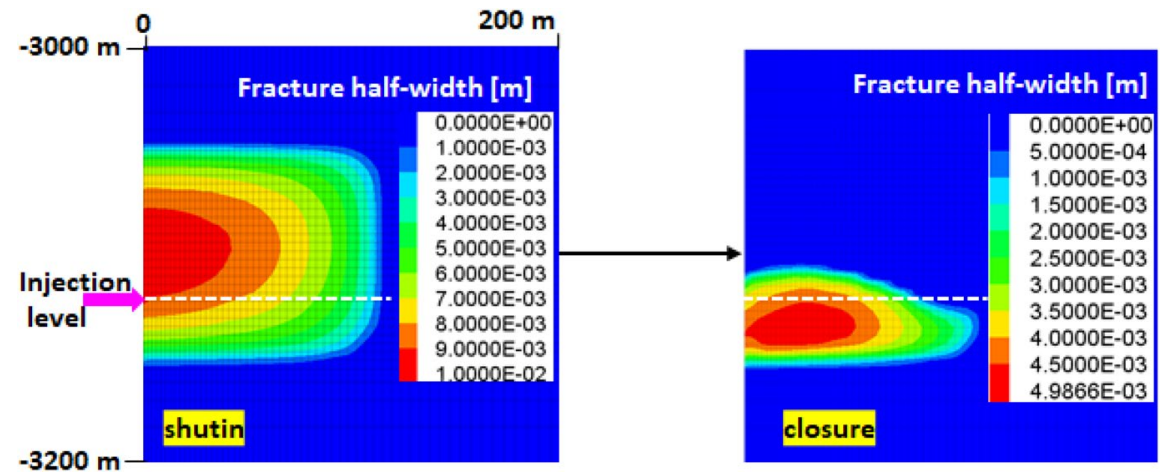

(2015). The applied stress state and pore pressure are provided in Fig. 6 b.

The hydraulic fracturing was conducted according to the injection plan presented in Fig. 6c. In addition, FLAC3D ${ }^{\text {plus }}$-TMVOC framework was used to conduct the hydraulic fracturing simulation with water-based guar gelled fluid (Liao, 2020). The fluid injection was performed at an injection rate of $6 \mathrm{~m}^{3} / \mathrm{min}$ for $80 \mathrm{~min}$, and the proppant injection started at $30 \mathrm{~min}$ and was continuously increased to a concentration of $500 \mathrm{~kg} /$ $\mathrm{m}^{3}$ until the end. The fracture geometry in terms of the half-width at shutin and closure is presented in Fig. 7, where it can be observed that proppants settled at the bottom of fracture and width is almost half at the closure.

\subsection{Fracture permeability and conductivity}

The data, such as stress state, pressure, and fracture geometry, are exported to the developed production model after fracturing. Then sensitivity analysis is performed for different proppant shapes, sizes, and 
strength parameters. The rod-shaped proppant diameter is $0.6 \mathrm{~mm}$ whereas the length varies. Thus, a proppant with a length and diameter of $0.6 \mathrm{~mm}$ has an aspect ratio of 1 . Considering the fracture width at closure as illustrated in Fig. 7, the generated porosity and permeability for different proppants can be observed in Fig. 8. Increasing the aspect ratio of the rod-shaped proppant significantly increases the porosity and permeability of fracture. Moreover, for the rod-shaped proppant with aspect ratio of 1 , the porosity and permeability are greater than the spherical proppant with the same diameter.

The fracture conductivity for proppants according to weighted dimensionless conductivity $\left(\mathrm{F}_{\text {cd,weighted }}\right)$, dimensionless conductivity $\left(\mathrm{F}_{\mathrm{cd}}\right)$ and conductivity $\left(\mathrm{F}_{\mathrm{c}}\right)$ are illustrated in Fig. 9. Due to the higher permeability, the fracture conductivity increases for larger proppants. However, the proppant with a higher aspect ratio may undergo more deformation or crushing under stress.

\subsection{Effect of multilayer proppants on deformation}

The proppants deform under compaction. The compressive stress on proppants increases, as the reservoir pressure depletes due to production. Production simulation was performed for one year to analyze the effects of pressure depletion and rising effective stress on the fracture aperture due to proppant-proppant and proppant-formation interaction, where the bottomhole pressure (BHP) was reduced to $15 \mathrm{MPa}$. The pressure

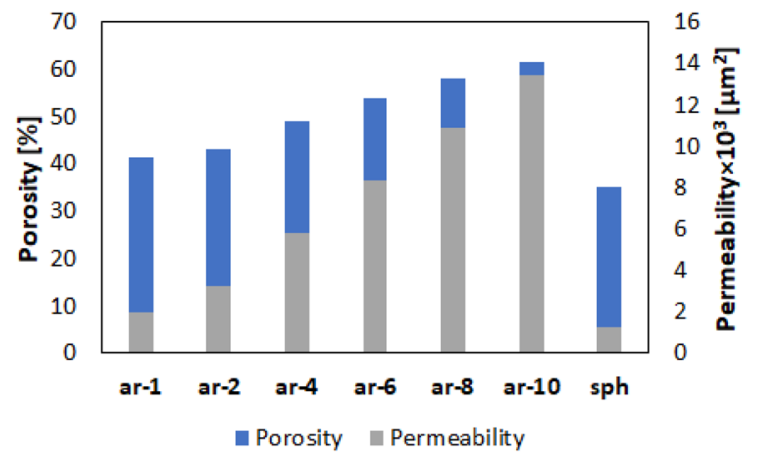

Fig. 8 Porosity and permeability of varying aspect ratio rodshaped proppants (ar: aspect ratio from 1-10, sph: spherical proppant)

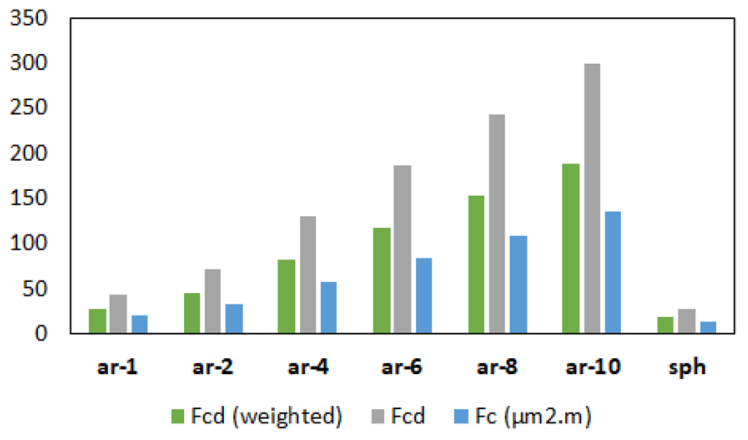

Fig. 9 Fracture conductivity based on different methods

and stress profile from shutin to one year of production is presented in Fig. 10.

Due to pressure depletion and the increase in effective stress, the fracture width reduces after one year of production (Fig. 11a). The change in fracture aperture can be observed from the change in contour color. Whereas Fig. 11b displays the fracture width profile along a-a' from Fig. 11a: at the end of injection (blue circles), after one year of depletion (gray circles) and the difference in fracture width between these two time points (red circles). The trend of change in fracture aperture $(\Delta w)$ indicates that increased fracture aperture reduction occurs, where the initial fracture width was higher due to additional layers of proppants undergoing deformation.

As a result, the fracture conductivity also decreases. Figure 12 depicts the ratio of reduced to the intial dimensionless fracture conductivity for different rod-shaped proppants with various aspect ratios. The proppants with a higher aspect ratio suffer

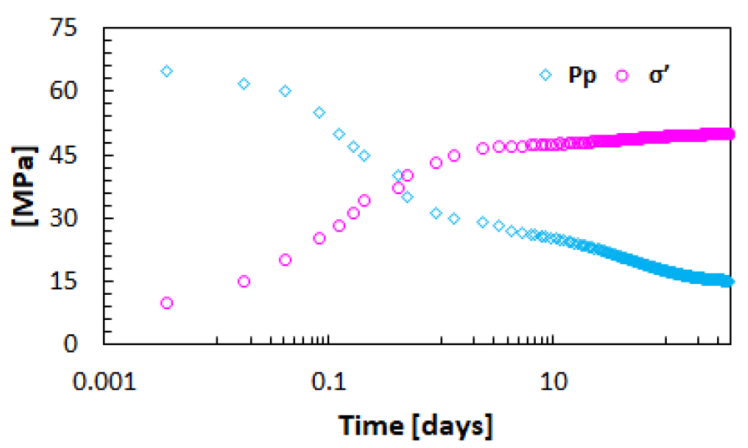

Fig. 10 Semi-log plot of the rise in effective stress due to the decline in production pressure over one year (Pp: pore pressure, $\sigma$ ': effective stress) 


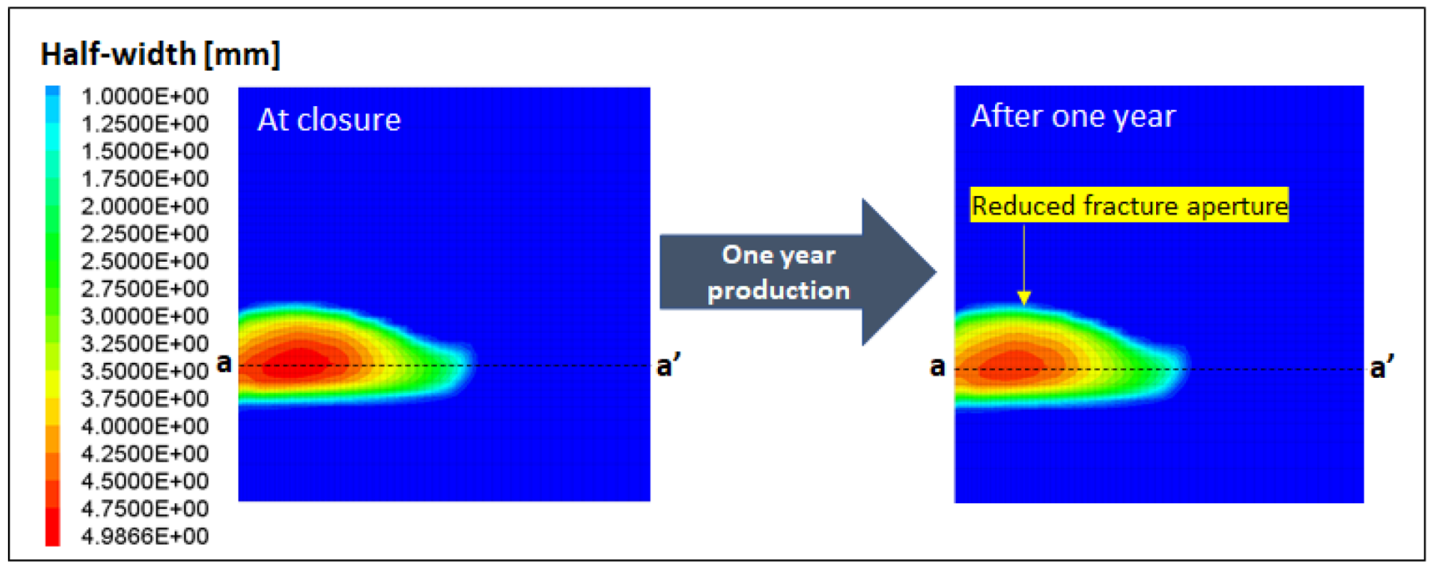

(a)

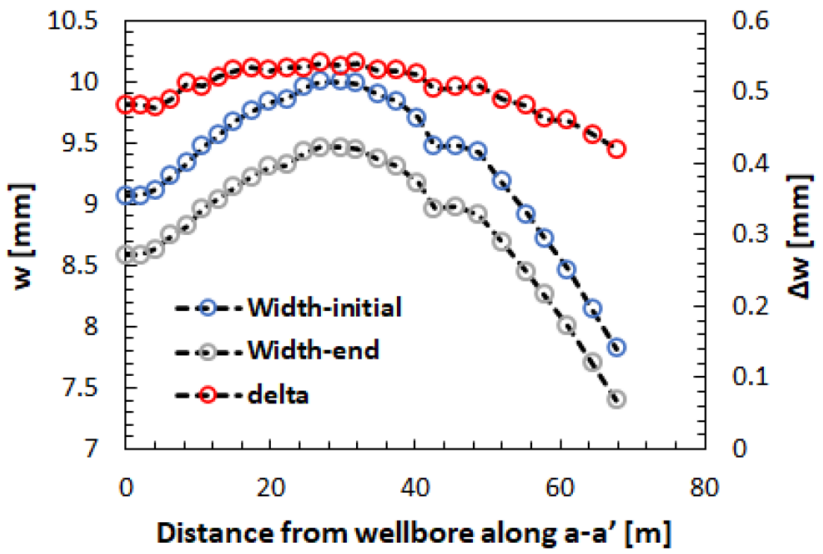

(b)

Fig. 11 a Reduced fracture aperture after one year of depletion and line a-a' at a horizontal distance from the wellbore b Change in the fracture width at a horizontal distance from the borehole along a- a' (w: width)

more deformation due to their large size; hence, maximum reduction in fracture conductivity is oberved for ar-10 proppant and minimum for ar-1 proppant.

\subsection{Strength contrast between proppant and formation}

The effect of strength contrast between the proppant and formation are analyzed by varying the elastic modulus of the proppants and formation using the same production time. The changes in fracture aperture due to the strength contrast and increasing stress are plotted in Fig. 13. The cases $\alpha 1, \alpha 2$ and $\alpha 3$ signified by the suffix e1 present the analysis of maintaining a constant formation elastic modulus at

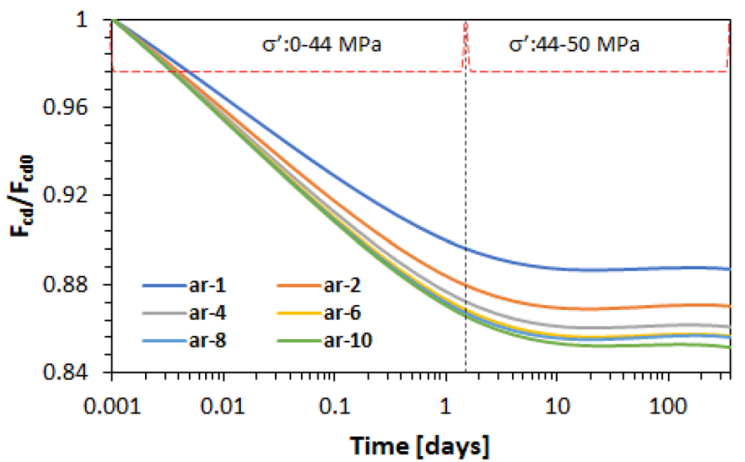

Fig. 12 Ratio of reduced $\left(\mathrm{F}_{\mathrm{cd}}\right)$ to initial $\left(\mathrm{F}_{\mathrm{cd} 0}\right)$ dimensionless conductivity after one year of production 
$20 \mathrm{GPa}$ and changing the proppant elastic modulus from 7 to $15 \mathrm{GPa}$, respectively. For e2, the proppant elastic modulus is kept constant at $20 \mathrm{GPa}$, and the formation elastic modulus is varied from 10 to 20 $\mathrm{GPa}$. If the proppant strength is less, the reduction in the fracture aperture would be more due to the higher proppant deformation. Moreover, a higher strength proppant would undergo less deformation and more embedment; however, the reduction in the fracture aperture would be less.

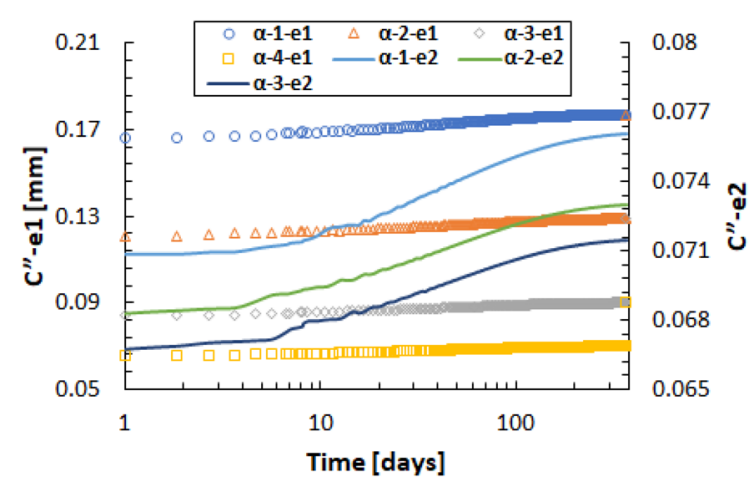

Fig. 13 Sensitivity analysis of the strength contrast between the proppant and formation. The e1 cases represent changing elastic modulus of the proppant and e 2 cases represent the changing elastic modulus of formation
4.4 Effect of bottomhole production pressure on the fracture aperture

Producing at higher rates requires higher drawdown by increasing the difference between BHP and reservoir pressure. This production places extra stress on the proppants as the pressure wave travels quickly in the fracture due to its higher permeability. Simulations were performed for the same one-year period but with different BHPs of $25 \mathrm{MPa}, 20 \mathrm{MPa}, 15 \mathrm{MPa}$ and $5 \mathrm{MPa}$ to investigate the effect of different production pressures on fracture aperture reduction. Lowering the BHP increases the stress on proppants; therefore, a greater reduction in the fracture aperture occurs (Fig. 14). Lower BHPs lead to higher production rates but cause more reduction in fracture conductivity due to the higher fracture width reduction (Fig. 14a). The relationship between the BHP and fracture aperture reduction is plotted in Fig. 14b.

\subsection{Long term production performance}

The long-term production performance of different proppants is investigated by simulating it for a period of 10 years. The results in terms of production rates and cumulative production for four cases (i.e., ar-1, 4, and 10 rod-shaped and spherical proppants) are presented in Fig. 15. The results demonstrate that changing the shape of the proppant can make a

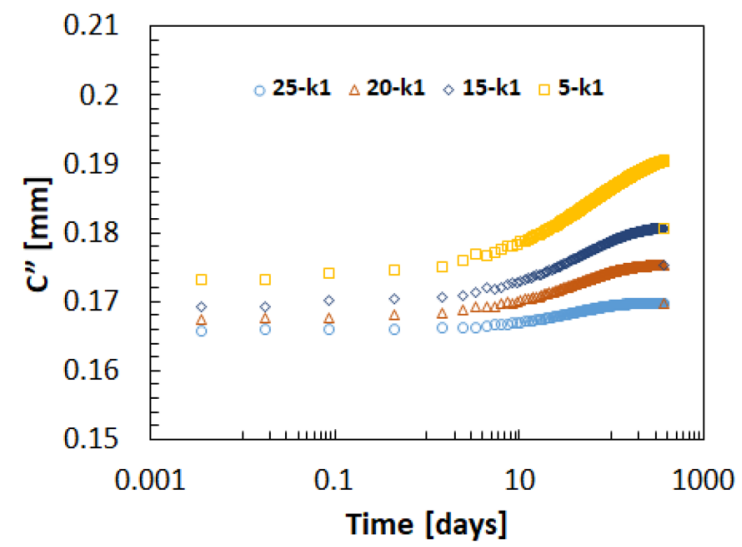

(a)

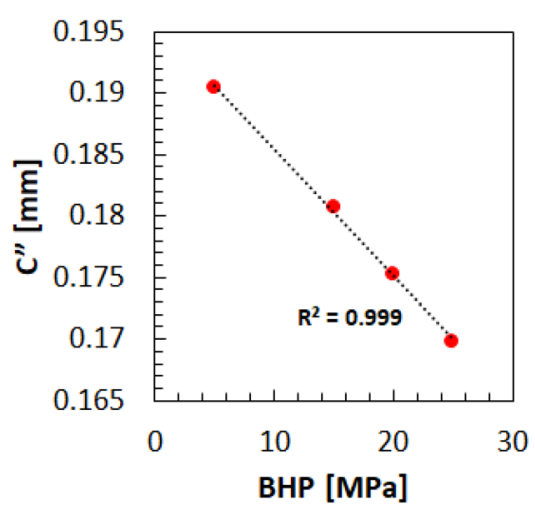

(b)

Fig. 14 a Effect of producing bottomhole pressure (BHP) on the fracture aperture reduction b relation between the change in fracture aperture and BHP 


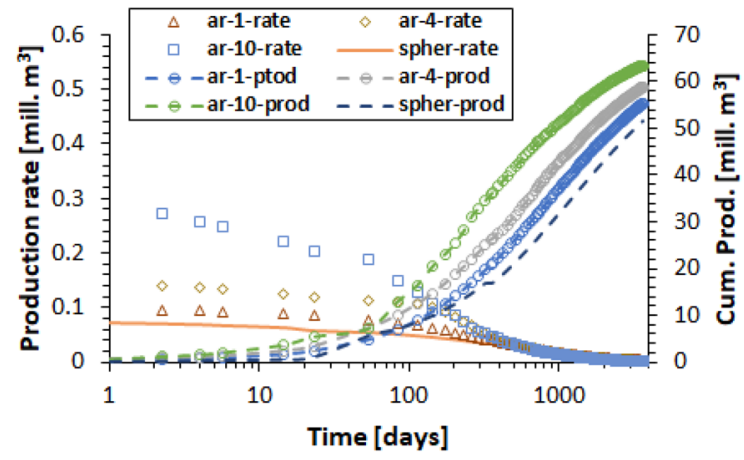

Fig. 15 Semi-log plot of production rates and the resultant cumulative production at the end of 10 years for different proppants (rate: production rate, prod: cumulative production, ar: aspect ratio and spher: spherical proppant)

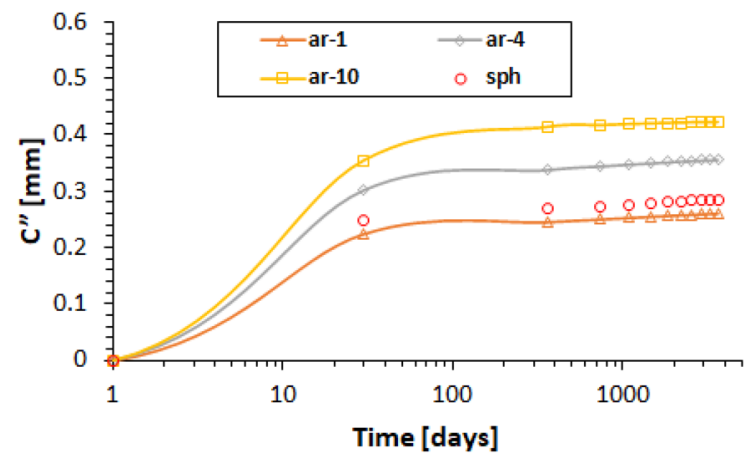

Fig. 16 Change in fracture aperture for different proppants over 10 years

considerable difference, as around $7 \%$ more recovery can be achieved using the same diameter rod-shaped proppant as that of the spherical proppant. Higher fracture conductivity due to the increased size of the rod-shaped proppant from ar 1 to 10 can notably increase the recovery by $13 \%$.

The BHP during the ten-year production period is decreased to $3 \mathrm{MPa}$, which increases the effective stress on the proppants. Therefore, the proppants embed and deform according to the stress conditions and strength contrast with the formation, reducing the fracture aperture (Fig. 16). The ar-10 suffered 38\% more deformation compared to ar-1 proppant in the same stress environment, reducing the fracture aperture by about $1 \mathrm{~mm}$.

\section{Case study}

\subsection{Background}

This section discusses the case study of well $\mathrm{x}$ in a tight gas reservoir in the North German basin. The 3D stratigraphic model and pressure and stress profiles are presented in Fig. 17a, b. The target formations include Wustrow, Dethlingen and Mirow. The mechanical and petrophysical properties of the formation are listed in Table 2. According to the P/Z analysis, the reservoir had initial reserves of 645 million $\mathrm{m}^{3}$ of gas. However, the hydraulic fracturing performed in 2000 did not improve the productive potential and only 2.016 million $\mathrm{m}^{3}$ of production could be taken (Mehmood et al. 2021).

First, the 3D model was verified through a pressure history match with the previously performed fracturing operation (Fig. 18a). The difference between the measured and simulated fracture pressure during the initial stage of fracturing was caused by the stoppage of stimulation operation as the radiator shaft on the blender sheared off. The presence of still-crosslinked gel in the wellbore led to very high tubing pressures. Consequently, a pressure match was not possible due to the abnormal pressure recorded. However, during this phase only $23.2 \mathrm{~m}^{3}$ fluid could be injected. The fracturing operation commenced the following day, and the injection rate was increased to planned $4.89 \mathrm{~m}^{3} / \mathrm{min}$ as the pressure dropped. Moreover, it can be observed from Fig. 18a that a reasonable pressure match was obtained during the main course of injection. Then, the production history match was performed to validate the numerical model, where the principal of superposition was applied for the matrix to fracture flow, the fracture permeability for the fracture flow, and matrix permeability for the fluid flow in the matrix (Fig. 18b). Production started in July 2000 and continued until April 2001 with intermittent shutin periods. The simulated fracture profile is presented in terms of the half-width and proppant distribution in Fig. 19a. It can be observed that the proppants settled at the bottom of fracture causing insufficient borehole-fracture connection. Consequently, the effectiveness of the fracturing operation for stimulating production was significantly 


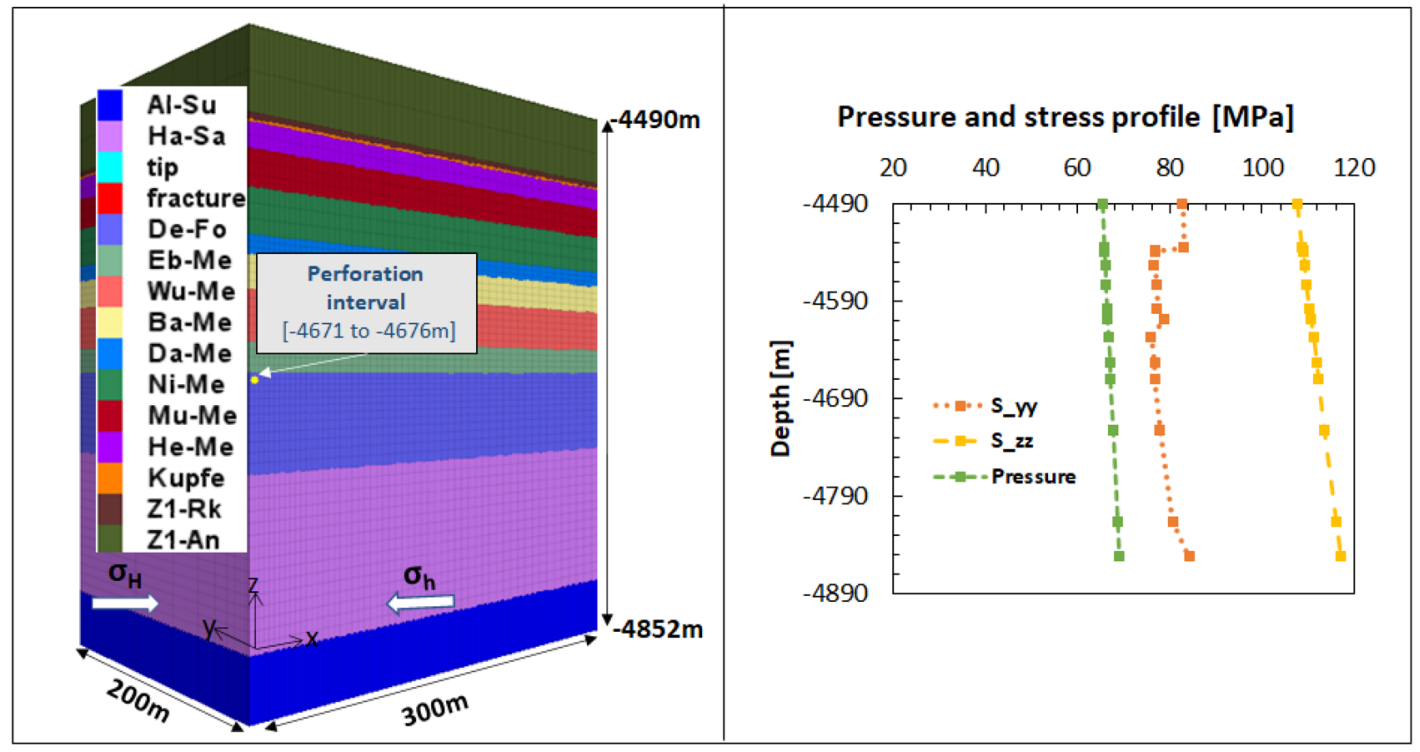

(a)

(b)

Fig. 17 a $1 / 43 \mathrm{D}$ stratigraphic model $\left(\sigma_{\mathrm{H}}\right.$ : maximum horizontal stress direction, $\sigma_{\mathrm{h}}$ : minimum horizontal stress direction) $\mathbf{b}$ pore pressure and stress profile

Table 2 Properties of the formations (Mehmood et al. 2021)

\begin{tabular}{lllllll}
\hline Formation & $\begin{array}{l}\text { Top depth } \\
\text { (TVD m) }\end{array}$ & Young's modulus (Pa) & Poisson's ratio (-) & Porosity (-) & Permeability $\left(\mathrm{m}^{2}\right)$ & Density $\left(\mathrm{kg} / \mathrm{m}^{3}\right)$ \\
\hline Z1-An & 4490 & $2.90 \times 10^{10}$ & 0.275 & 0.041 & $9.720 \times 10^{-21}$ & 2940 \\
Z1-Rk & 4535 & $2.85 \times 10^{10}$ & 0.253 & 0.044 & $4.84 \times 10^{-17}$ & 2840 \\
Kupfe & 4538 & $2.89 \times 10^{10}$ & 0.260 & 0.059 & $3.15 \times 10^{-19}$ & 2715 \\
He-Me & 4540 & $2.94 \times 10^{10}$ & 0.255 & 0.040 & $1.05 \times 10^{-16}$ & 2705 \\
Mu-Me & 4554 & $3.06 \times 10^{10}$ & 0.206 & 0.068 & $2.78 \times 10^{-16}$ & 2655 \\
Ni-Me & 4574 & $3.72 \times 10^{10}$ & 0.220 & 0.001 & $1.00 \times 10^{-21}$ & 2750 \\
Da-Me & 4598 & $3.31 \times 10^{10}$ & 0.230 & 0.081 & $1.154 \times 10^{-16}$ & 2574 \\
Ba-Me & 4609 & $3.01 \times 10^{10}$ & 0.197 & 0.110 & $1.165 \times 10^{-16}$ & 2500 \\
Wu-Me & 4627 & $2.93 \times 10^{10}$ & 0.2025 & 0.110 & $4.887 \times 10^{-16}$ & 2493 \\
Eb-Me & 4654 & $2.76 \times 10^{10}$ & 0.200 & 0.110 & $8.430 \times 10^{-16}$ & 2707 \\
De-fo & 4670 & $2.65 \times 10^{10}$ & 0.1975 & 0.113 & $5.79 \times 10^{-16}$ & 2668 \\
$\mathrm{Ha}-\mathrm{Sa}$ & 4723 & $2.61 \times 10^{10}$ & 0.2267 & 0.113 & $9.504 \times 10^{-16}$ & 2668 \\
$\mathrm{Al}-\mathrm{Su}$ & 4816 & $2.92 \times 10^{10}$ & 0.25 & 0.064 & $1.067 \times 10^{-20}$ & 2750 \\
\hline
\end{tabular}

reduced. Thus, the cumulative production was limited to only 2.016 million $\mathrm{m}^{3}$ (Fig. 18b). The pressure profile of the reservoir at different time points during production is displayed in Fig. 19b.

Mehmood et al. (2021) proposed hydraulic fracturing with n-heptane (alkane) to minimize issues, such as the delayed fracture closure and poor cleanup efficiency associated with conventional water-based fluids. After extensive sensitivity analyses, two proposals were presented for optimizing well $\mathrm{x}$. The injection schedule and fracture geometry of two hydraulic fracturing proposals with 


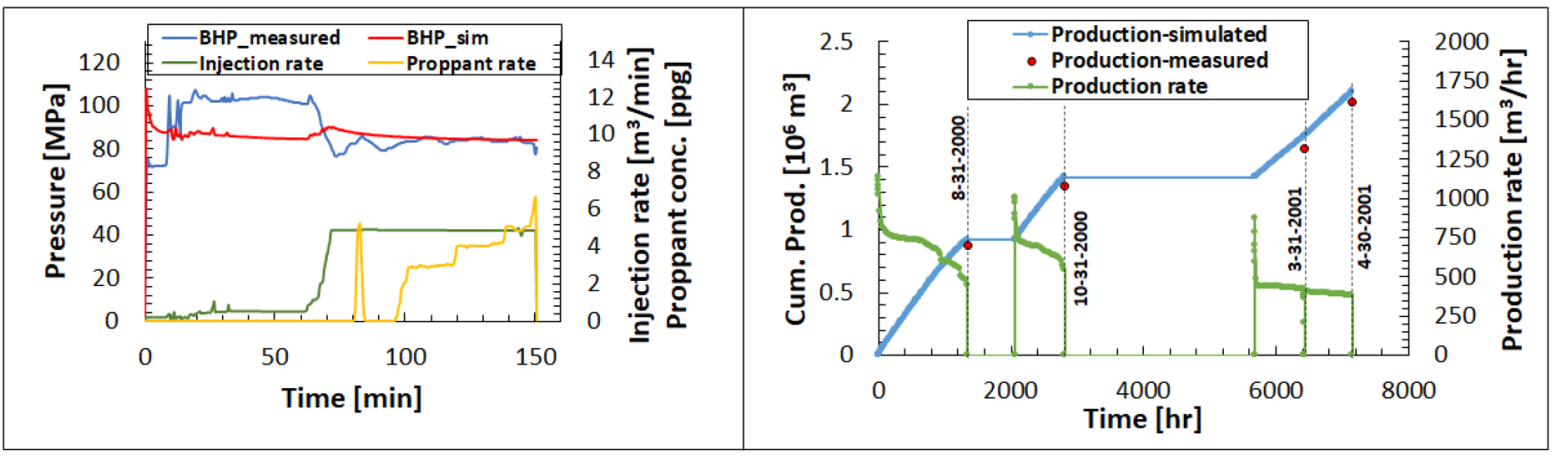

(a)

(b)

Fig. 18 a Fracture pressure history match: comparison of simulated (sim) and measured data according to the injection schedule (Mehmood et al. 2021) b production history match with specification of data points according to date

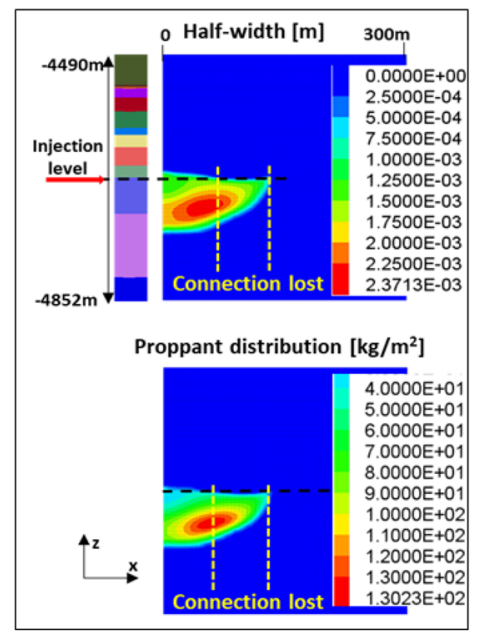

(a)

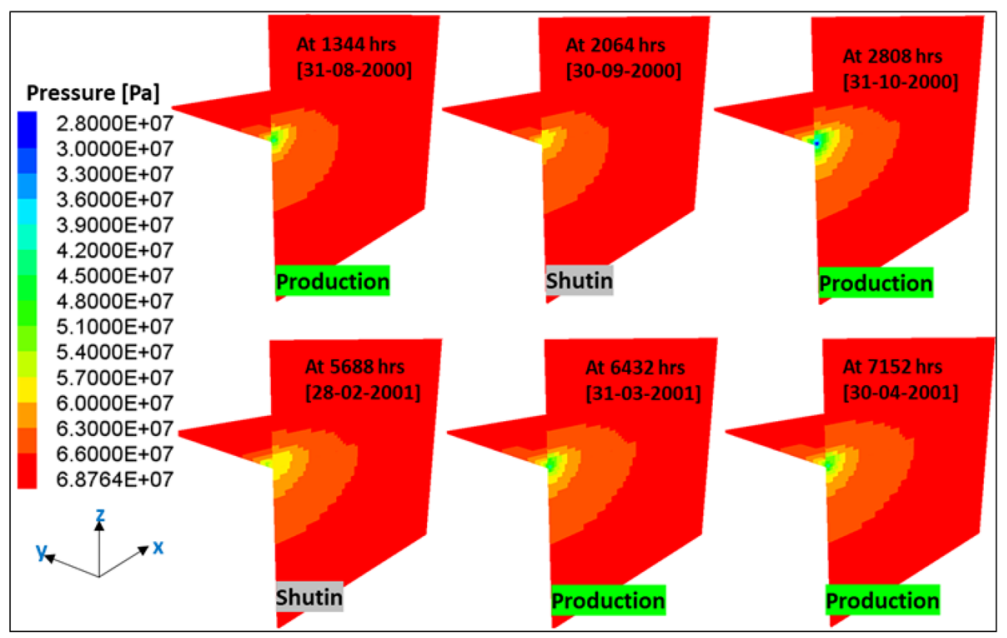

(b)

Fig. 19 a Fracture profile according to the half-width and proppant distribution at closure (600 min) and b reservoir pressure profile at different stages of production

alternative fluid (n-heptane) according to their fracture width profile are depicted in Fig. 20a, b. Injection rates of $6 \mathrm{~m}^{3} / \mathrm{min}$ and $8 \mathrm{~m}^{3} / \mathrm{min}$ were employed for design proposals 1 and 2, respectively. The fluid viscosity for both cases was $0.15 \mathrm{~Pa} \mathrm{~s}$, and the injection period was $105 \mathrm{~min}$.

However, this work is limited to investigating the influence of rod-shaped proppants on recovery improvement. The next section, therefore, is dedicated to the consideration of rod-shaped proppants in the fracture proposals 1 and 2 .

\subsection{Application of rod-shaped proppant}

The fracture geometry, stress state, and pressure profile of the two proposals were imported in the developed model. Figure 21 illustrates the fracture conductivity based on different proppant shapes and sizes for the design proposals. Due to the higher porosity of rod-shaped proppant pack, increased conductivity is offered compared to spherical proppants. The maximum conductivity significantly increases from $9.175 \times 10^{-13} \mathrm{~m}^{2} . \mathrm{m}$ to $4.54 \times 10^{-12} \mathrm{~m}^{2} . \mathrm{m}$ 

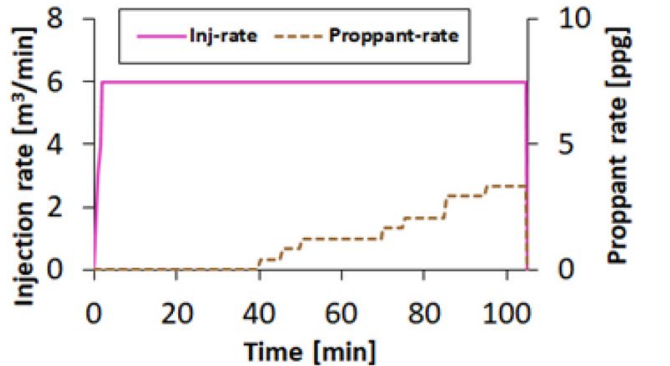

(a)

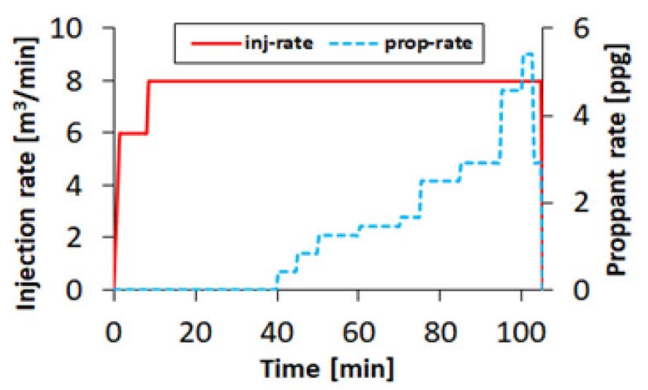

(b)
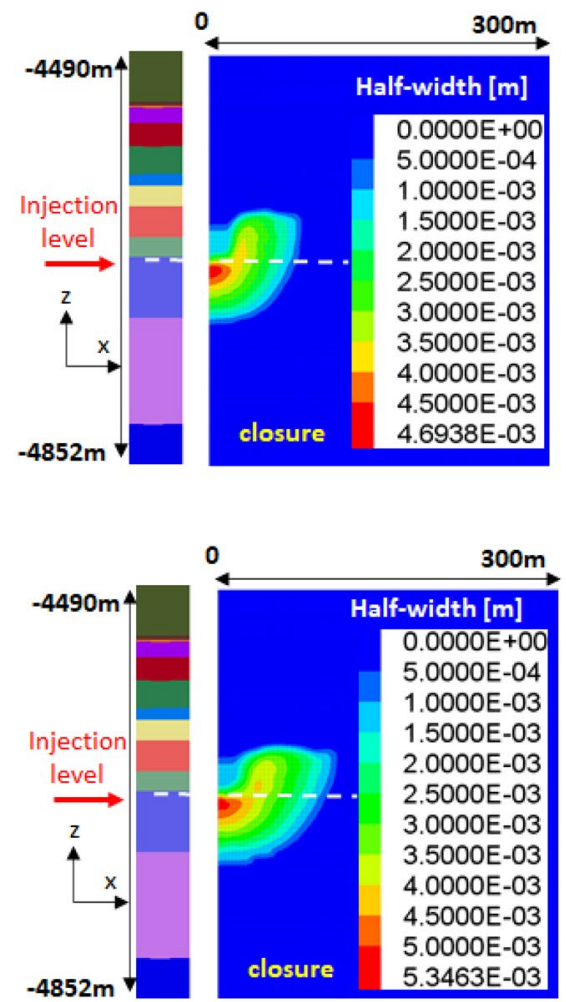

Fig. 20 a Injection schedule and fracture profile at closure for proposal 1 and $\mathbf{b}$ injection schedule and fracture profile at closure for proposal 2 (Inj.rate: injecrtion rate; prop-rate: proppant rate)

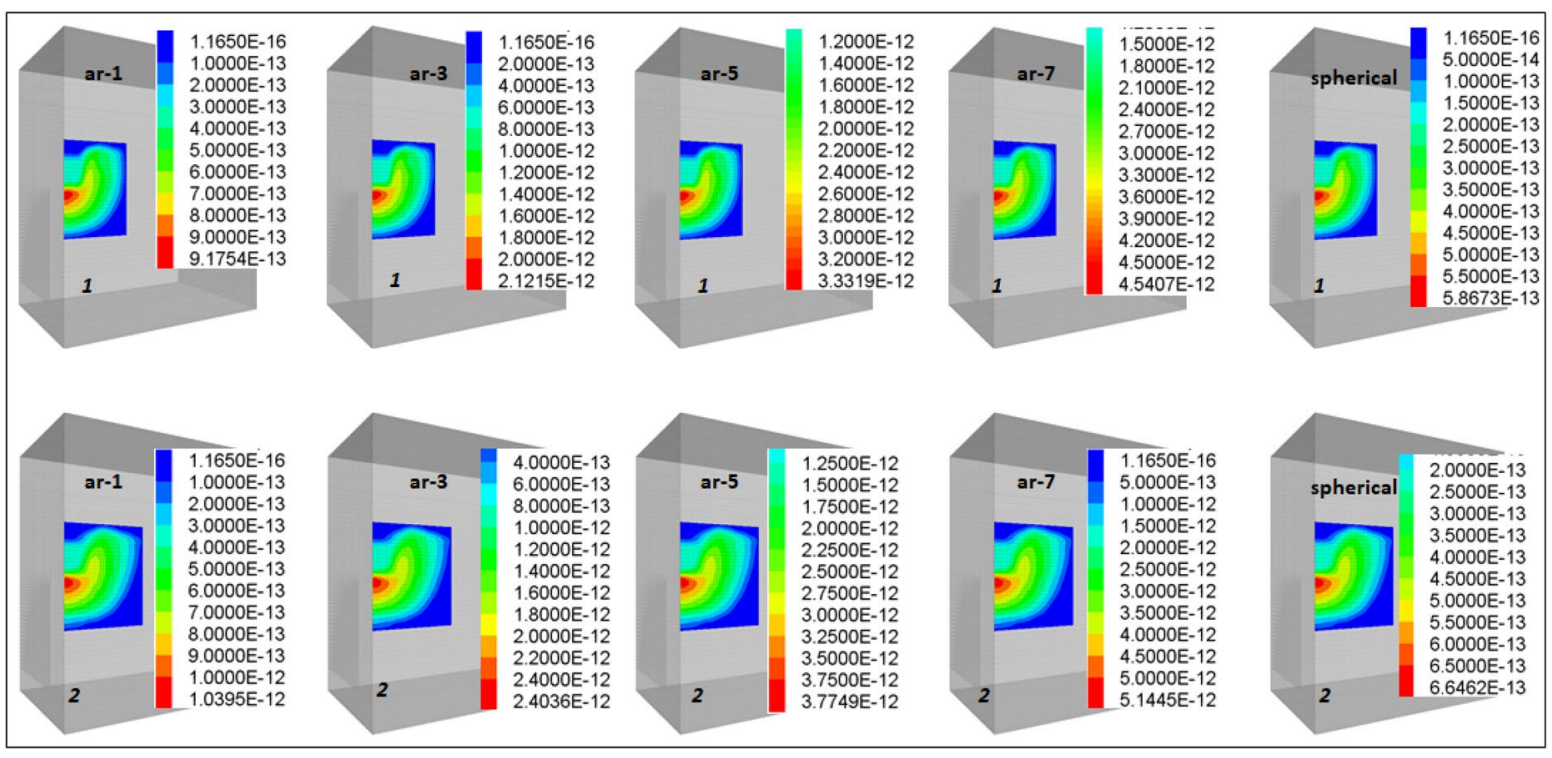

Fig. 21 Fracture conductivity kf.w $\left(\mathrm{m}^{2} . \mathrm{m}\right)$ for proposals 1 and 2 for spherical and different aspect ratios (ar) rod-shaped proppants 
Table 3 Ten-year production forecast

\begin{tabular}{llll}
\hline Proppant type and dimensions & \multicolumn{2}{l}{ Production forecast (million $\mathrm{sm}^{3}$ ) } \\
\cline { 3 - 4 } & & Proposal-1 & Proposal-2 \\
\hline Rod-shaped (aspect ratio: 1) & $\begin{array}{l}\mathrm{d}_{\mathrm{r}}: 0.6 \mathrm{~mm} \\
\mathrm{~d}_{\mathrm{r}}: 0.6 \mathrm{~mm}\end{array}$ & 172 & 181 \\
Rod-shaped (aspect ratio: 3) & $\begin{array}{l}\mathrm{d}_{\mathrm{r}}: 1.8 \mathrm{~mm} \\
\mathrm{~d}_{\mathrm{r}}: 0.6 \mathrm{~mm}\end{array}$ & 182 & 192 \\
Rod-shaped (aspect ratio: 5) & $\begin{array}{l}\mathrm{d}_{\mathrm{r}}: 3.0 \mathrm{~mm} \\
\mathrm{~d}_{\mathrm{r}}: 0.6 \mathrm{~mm}\end{array}$ & 188 & 199 \\
Rod-shaped (aspect ratio: 7) & $\begin{array}{l}\mathrm{d}_{\mathrm{r}}: 4.2 \mathrm{~mm} \\
\mathrm{~d}_{\mathrm{r}}: 0.6 \mathrm{~mm}\end{array}$ & 193 & 204 \\
Spherical & $\mathrm{d}_{\mathrm{r}}: 0.6 \mathrm{~mm}$ & 160 & 168 \\
\hline
\end{tabular}

(917.5-4540.7 $\mathrm{mD} \mathrm{m}$ ), as the proppant aspect ratio increases from 1 to 7 for proposal 1. For proposal 2 , increasing the aspect ratio from 1 to 7 notably increases the conductivity from $1.039 \times 10^{-12} \mathrm{~m}^{2} \mathrm{~m}$ to $5.144 \times 10^{-12} \mathrm{~m}^{2} \mathrm{~m}(1039.5$ to $5144.5 \mathrm{mD} \mathrm{m})$. In contrast, spherical proppants provide lower fracture conductivity than rod-shaped proppant with an aspect ratio of 1 . For proposal 1, a maximum fracture conductivity of $5.867 \times 10^{-13} \mathrm{~m}^{2} \mathrm{~m}(586.7 \mathrm{mD} \mathrm{m})$ for spherical proppant is achieved which is considerably lower than $9.1754 \times 10^{-13} \mathrm{~m}^{2} \mathrm{~m}(917.5 \mathrm{mD} \mathrm{m})$ for same diameter aspect ratio 1 rod-shaped proppant. Similarly, aspect ratio 1 rod-shaped proppant resulted in a conductivity of $1.0395 \times 10^{-12} \mathrm{~m}^{2} . \mathrm{m}(1039.5$ mD.m) in comparison with $6.646 \times 10^{-13} \mathrm{~m}^{2} \mathrm{~m}$ $(664.6 \mathrm{mD} \mathrm{m})$, in proposal 2 respectively. Furthermore, the reason for different conductivities for similar size proppants in proposals 1 and 2 is the difference in their fracture geometries.
Therefore, due to higher conductivity, rod-shaped proppants can further enhance the production from wellbore $x$. The production forecast over 10 years for rod-shaped and spherical proppants was performed to analyze their effects on recovery. The production forecasts for proposals 1 and 2 with different proppants are presented in Fig. 22 and tabulated (Table 3).

Compared to the previous fracture job, a significant recovery increase can be achieved using proposal with conventional spherical proppants. However, rodshaped proppants can further improve recovery. Specifically, a $6.9-7.1 \%$ recovery increase is observed when using a rod-shaped proppant with an aspect aspect ratio of 1 , with the same diameter as the spherical proppant. The difference in the production while changing proppant size from an aspect ratio of 1 to 3,3 to 5 and 5 to 7 is approximately $5.5 \%, 3.1 \%$ and $2.59 \%$, respectively. Therefore, increasing the proppant size increases the recovery, however the increase in recovery ratio decreases as the proppants undergo

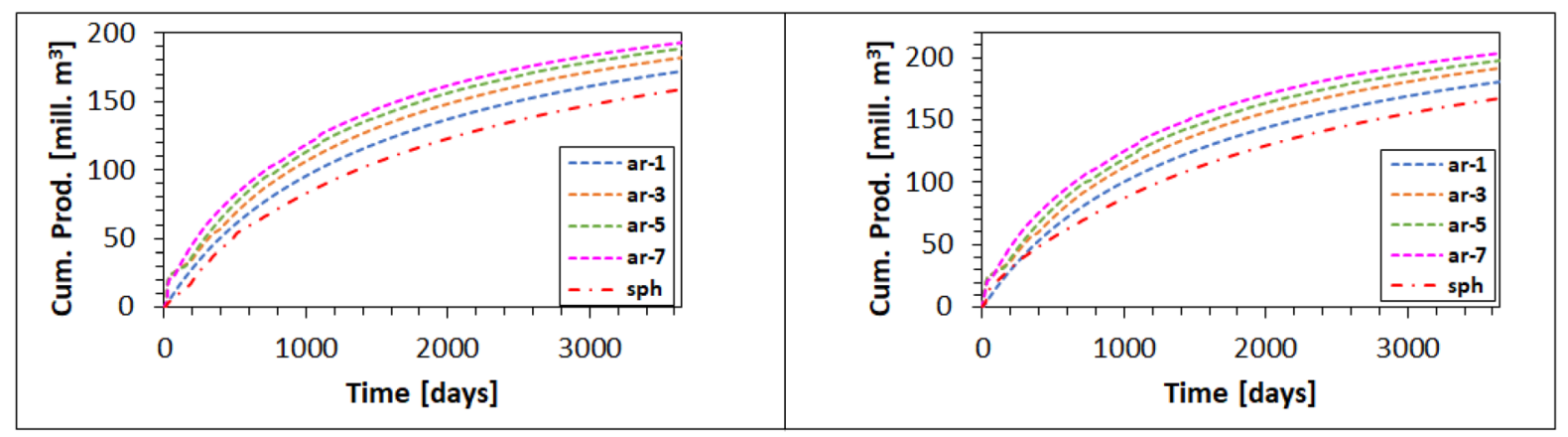

(a)

(b)

Fig. 22 Production forecast based on different proppants for a proposal 1 and $\mathbf{b}$ proposal 2 


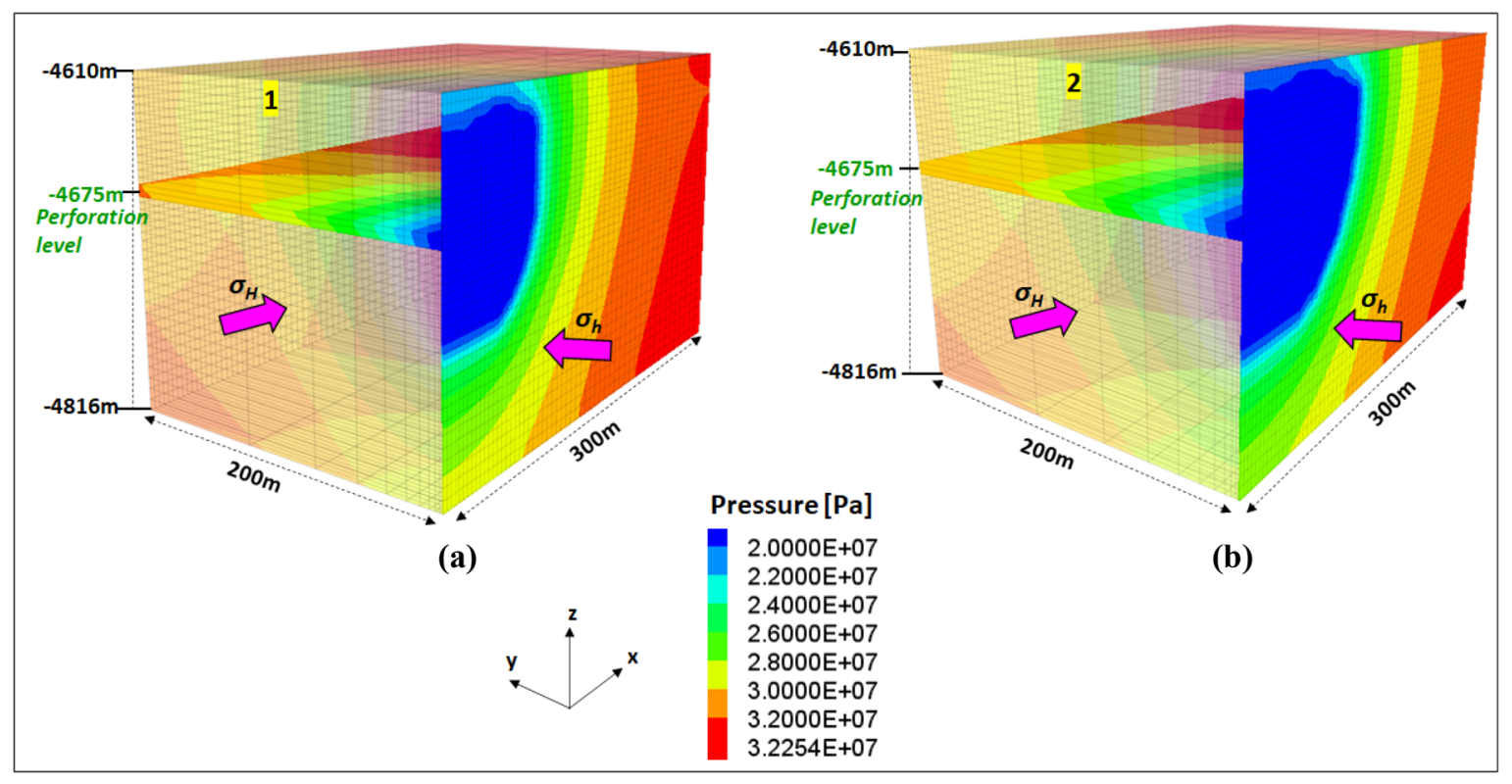

Fig. 23 Pressure depletion after 10 years of production for a proposal 1 and $\mathbf{b}$ proposal 2

more deformation and crushing due to larger size. The pressure profile after production is presented in Fig. 23.

\section{Conclusions}

Proppants keep the fracture open once the pressurized fluid injection is stopped after hydraulic stimulation. The fracture conductivity, a measure of production potential, depends on the porosity and permeability of the proppant pack. Therefore, changing the shape of the proppant can make a significant difference. Rod-shaped proppants unlike spherical proppants are not symmetrical about their axes. Thus, numerous packing arrangements are possible, offering higher fracture conductivity. This higher fracture conductivity can considerably increase the productivity from hydraulically fractured geo-resource of tight gas reservoirs. The following conclusions can be drawn based on this research work:

(a) Proppants of sufficient strength should be used. Deformation is higher for lower strength proppants. For proppants with significantly higher strength than formation, embedment is greater. In addition, high-strength rod-shaped proppants should be used to avoid unnecessary deformation or crushing due to their cylindrical shape. Moreover, zones with more proppant layers undergo more width reduction due to proppant-proppant interaction.

(b) Apart from the existing stress environment, the producing BHP also contributes to fracture aperture reduction. If the pressure gradient between the formation and bottomhole is too high, then the effective stress on the proppants increases, which can increase the rate of reduction in fracture conductivity.

(c) To investigate the long-term production performance, simulation was performed for a 10 -year period. Increasing the aspect ratio from 1 to 10 significantly increased the recovery by $13 \%$. However, increasing the size of the proppant causes more deformation and reduction in fracture aperture and conductivity. In the well $\mathrm{x}$ case study, the difference in the production while changing proppant size from an aspect ratio of $1-3,3-5$ and $5-7$ is approximately $5.5 \%, 3.1 \%$ and $2.59 \%$, respectively. Therefore, aspect ratio 3 rod-shaped proppant can be a better choice for the discussed case study. However, the proppant selection varies from field to field due to different formation properties, stress state and fracture 
geometries. Therefore, a suitable size proppant should be chosen for optimum recovery. Moreover, replacing the spherical proppant with a similar diameter aspect ratio-1 rod-shaped proppant can increase the recovery significantly $(7 \%)$.

(d) The application of rod-shaped proppants to fracture design proposals of well $\mathrm{x}$ can further improve productivity compared with spherical proppants.

The simulation results are encouraging. Therefore, rod-shaped proppants are recommended as propping agents for hydraulic stimulation of tight gas reservoirs. The development and implementation of a numerical model for rod-shaped proppant transport and settling will be considered in the FLAC3DTMVOC framework for future work.

Funding Open Access funding enabled and organized by Projekt DEAL. This research was funded by the Deutsche Wissenschaftliche Gesellschaft für Erdöl, Erdgas und Kohle e.V.: DGMK-Project 814 . The authors would like to express their sincere gratitude to S. Kuchling (DGMK, Hamburg) for project coordination and all the project partners for their support, guidance, and informative discussions: D. Leuchtmann (Wintershall Dea GmbH, Hamburg), M. Zinterl (ExxonMobil Production Deutschland GmbH, Hanover), M. Berling (Neptune Energy Deutschland GmbH, Lingen) and J. Sommer (Wintershall Dea $\mathrm{GmbH}$, Kassel). We are especially thankful to $\mathrm{M}$. Zinterl (ExxonMobil Production Deutschland GmbH, Hanover) for providing the data.

Availability of data and materials The data and material have been presented in this article and relevant references have been cited.

Code availability FLAC3D and TMVOC (TOUGH) are licensed software and therefore require licensing from respective developers.

\section{Declarations}

Conflicts of interest On behalf of all authors, the corresponding author states that there is no conflict of interest.

Open Access This article is licensed under a Creative Commons Attribution 4.0 International License, which permits use, sharing, adaptation, distribution and reproduction in any medium or format, as long as you give appropriate credit to the original author(s) and the source, provide a link to the Creative Commons licence, and indicate if changes were made. The images or other third party material in this article are included in the article's Creative Commons licence, unless indicated otherwise in a credit line to the material. If material is not included in the article's Creative Commons licence and your intended use is not permitted by statutory regulation or exceeds the permitted use, you will need to obtain permission directly from the copyright holder. To view a copy of this licence, visit http://creativecommons.org/licenses/by/4.0/.

Open Access This article is licensed under a Creative Commons Attribution 4.0 International License, which permits use, sharing, adaptation, distribution and reproduction in any medium or format, as long as you give appropriate credit to the original author(s) and the source, provide a link to the Creative Commons licence, and indicate if changes were made. The images or other third party material in this article are included in the article's Creative Commons licence, unless indicated otherwise in a credit line to the material. If material is not included in the article's Creative Commons licence and your intended use is not permitted by statutory regulation or exceeds the permitted use, you will need to obtain permission directly from the copyright holder. To view a copy of this licence, visit http://creativecommons.org/licenses/by/4.0/.

\section{References}

Carpenter C (2016) Rod-shaped-proppant fracturing boosts production and adds reserves. J Pet Technol 68:70-98. https://doi.org/10.2118/0316-0070-JPT

Cheremisin AN, Zinchenko A, Lecerf B, Pavlova S, Thompson KE, Lane N (2011) A unique, large-scale computer tomography scanner: investigation of fracture cleanup with different materials. Presented at SPE hydraulic fracturing technology conference, The Woodlands, Texas, USA, Jan 2011.

Clark JB (1949) A hydraulic process for increasing the productivity of wells. J Pet Technol 1:1-8. https://doi.org/10. 2118/949001-G

Economides MJ (2007) Modern fracturing: enhancing natural gas production. Houston, Texas

Economides MJ, Nolte KG (2000) Reservoir stimulation. Sugar Land, Texas

EIA (2019) International Energy Outlook 2019 with projections to 2050. US Energy Information Administration, Office of Energy Analysis, US Department of Energy, Washington, DC

Gou Y, Zhou L, Zhao X, Hou Z, Were P (2015) Numerical study on hydraulic fracturing in different types of georeservoirs with consideration of $\mathrm{H}^{2} \mathrm{M}$-coupled leak-off effects. Environ Earth Sci 73:6019-6034. https://doi. org/10.1007/s12665-015-4112-5

Hellmann JR, Scheetz BE, Luscher WG, Hartwich DG, Koseski RP (2009) Engineering ceramics for stimulation of unconventional energy resources. Am Ceram Soc Bull 93:28-35

Hou MZ, Li M, Gou Y, Feng W (2021) Numerical simulation and evaluation of the fracturing and tight gas production with a new dimensionless fracture conductivity (FCD) model. Acta Geotech 16:985-1000. https://doi.org/10. 1007/s11440-020-01079-4 
IEA (2020) Global energy review 2019: the latest trends in energy and emissions in 2019. Int Energy Agency. https://doi.org/10.1787/90c8c125-en

ITASCA (2009) FLAC3D: Fast Lagrangian analysis of continua in 3 dimensions, Version 4.0. Itasca Consulting Group Inc., Minneapolis

Jia C (2017) Breakthrough and significance of unconventional oil and gas to classical petroleum geology theory. Pet Explor Dev 44:1-10. https://doi.org/10.1016/S18763804(17)30002-2

Jia L, Li K, Zhou J, Yan Z, Wan F, Kaita M (2019) A mathematical model for calculating rod-shaped proppant conductivity under the combined effect of compaction and embedment. J Pet Sci Eng 180:11-21. https://doi.org/10. 1016/j.petrol.2019.05.034

Leimkuhler J, Leveille G (2012) Unconventional resources. Way Ahead 08:26-28. https://doi.org/10.2118/ 0112-026-TWA

Li G, Li X-S, Li C (2017) Measurement of permeability and verification of Kozeny-Carman equation using statistic method. Energy Procedia 142:4104-4109. https://doi. org/10.1016/j.egypro.2017.12.332

Li K, Gao Y, Lyu Y, Wang M (2015) New mathematical models for calculating proppant embedment and fracture conductivity. Soc Pet Eng J 20:496-507. https://doi.org/ 10.2118/155954-PA

Li M (2018) Optimization of multistage hydraulic fracturing treatment for maximization of the tight gas productivity. Dissertation, Clausthal University of Technology

Liang F, Sayed M, Al-Muntasheri GA, Chang FF, Li L (2016) A comprehensive review on proppant technologies. Petroleum 2:26-39. https://doi.org/10.1016/j. petlm.2015.11.001

Liao J (2020) Development of coupled THM models for reservoir stimulation and geo-energy production with supercritical $\mathrm{CO}_{2}$ as working fluid. Dissertation, Clausthal University of Technology

Mehmood F, Hou MZ, Liao J, Haris M, Cao C, Luo J (2021) Multiphase multicomponent numerical modeling for hydraulic fracturing with n-heptane for efficient stimulation in a tight gas reservoir of Germany. Energies 14(11):3111. https://doi.org/10.3390/en14113111

McDaniel GA, Abbott J, Mueller FA, Anwar AM, Pavlova S, Nevvonen O, Parias T, Alary J (2010) Changing the shape of fracturing: new proppant improves fracture conductivity. Presented at the SPE annual technical conference and exhibition, Florence, Italy 19-22 Sept 2010. https://doi.org/10.2118/135360-MS

Montgomery CT, Smith MB (2010) Hydraulic fracturing: history of an enduring technology. J Pet Technol 62:26-40. https://doi.org/10.2118/1210-0026-JPT

Osiptsov AA (2017) Hydraulic fracture conductivity: effects of rod-shaped proppant from lattice-Boltzmann simulations and lab tests. Adv Water Resour 104:293-303. https://doi. org/10.1016/j.advwatres.2017.04.003
Prats M (1961) Effect of vertical fractures on reservoir behavior-incompressible fluid case. Soc Pet Eng J 1:105-118. https://doi.org/10.2118/1575-G

Pruess K, Batistelli A (2002) TMVOC, a numerical simulator for three-phase non-isothermal flows of multicomponent hydrocarbon mixtures in saturated-unsaturated heterogenous media. Lawrence Berkeley National Laboratory, Berkeley

Schlumberger (2013) RodPROP: high-aspect ratio proppant. https://www.slb.com/-/media/files/stimulation/productsheet/rodprop-ps. Accessed 28 Sept 2020

Schlumberger (2015) HiWAY technique and rod-shaped proppant increase fracturing efficiency $99 \%$ in depleted formations. https://www.slb.com/resource-library/case-study/st/ hiway-rodprop-devonian-cs. Accessed 29 Dec 2020

Soetikno L, Artola PD, Guimaraes C (2014) Novel rod-shaped proppant fracturing boosts production and adds recoverable reserves in Indonesia during hydraulic fracturing field revival campaign. Presented at the international petroleum technology conference, Kuala Lumpur, Malaysia, 10-12 Dec 2014. https://doi.org/10.2523/IPTC-18086-MS

US EIA. How much carbon dioxide is produced when different fuels are burned? Independent Statistics \& Analysis, U.S. Energy Information Administration. https://www.eia.gov/ tools/faqs/faq.php?id=73\&t=11. Accessed 18 Aug 2021.

Wang J, Bentley Y (2020) Modelling world natural gas production. Energy Rep 6:1363-1372. https://doi.org/10.1016/j. egyr.2020.05.018

Wilson A (2015) Unconventional proppant combined with channel fracturing increases effectiveness. J Pet Technol 67:89-93. https://doi.org/10.2118/0315-0089-JPT

Zhou L, Hou MZ (2013) A new numerical 3D-model for simulation of hydraulic fracturing in consideration of hydromechanical coupling effects. Int J Rock Mech Min Sci 60:370-380. https://doi.org/10.1016/j.ijrmms.2013.01.006

Zou C, Yang Z, Zhang G, Hou L, Zhu R, Tao S, Yuan X, Dong D, Wang Y, Guo Q, Wang L, Bi H, Li D, Wu N (2014) Conventional and unconventional petroleum "orderly accumulation": concept and practical significance. Pet Explor Dev 41:14-30. https://doi.org/10.1016/S18763804(14)60002-1

Zou C, Zhang G, Yang Z, Tao S, Hou L, Zhu R, Yuan X, Ran Q, Li D, Wang Z (2013) Concepts, characteristics, potential and technology of unconventional hydrocarbons: on unconventional petroleum geology. Pet Explor Dev 40:413-428. https://doi.org/10.1016/S1876-3804(13) 60053-1

Publisher's Note Springer Nature remains neutral with regard to jurisdictional claims in published maps and institutional affiliations. 